\title{
Causal Mechanisms in Organization and Innovation Studies
}

Peter Hedström, Linköping University

Karl Wennberg, Linköping University 


\title{
Causal Mechanisms in Organization and Innovation Studies*
}

Forthcoming in Innovation: Organization \& Management.

\author{
Peter Hedström \\ Institute of Analytical Sociology (IAS) \\ Linköping University \\ 60174 Norrköping \\ Sweden \\ E-mail: peter.hedstrom@liu.se
}

\author{
Karl Wennberg** \\ Department of Management and Engineering (IEI) \\ Institute of Analytical Sociology (IAS) \\ Linköping University \\ 60174 Norrköping \\ Sweden \\ E-mail: karl.wennberg@liu.se
}

Keywords: Research Methods, Mechanisms, Causality, Theory

\footnotetext{
* We are grateful for feedback from Gregoire Crodieu, Phil Kim, Markus Perkmann, Petri Ylikoski, and seminar participants at the Institute of Analytical Sociology (IAS) at Linköping University. The usual caveats apply. We gratefully acknowledge financial support from the European Research Council (324233) and Riksbankens Jubileumsfond (M12-0301:1).

** Corresponding author.
} 


\section{Causal Mechanisms in Organization and Innovation Studies}

Abstract: We outline the guiding ideas behind mechanisms-based theorizing in analytical sociology as a fruitful alternative to economics-inspired research on identification of causal effects, and discuss the potential of mechanisms-based theorizing for further development in organization and innovation studies. We discuss the realist stance on providing broader explanations as an identifying characteristic of the mechanism approach, its focus on the dynamic processes through which outcomes to be explained are brought about, and outline theoretical and methodological implications for organization and innovation studies.

Keywords: Research Methods, Mechanisms, Causality

\section{Introduction}

During the last decades, mechanisms and mechanism-based explanations have received considerable attention in many branches of the social sciences as well as in the philosophy of science (see Hedström \& Ylikoski 2010). Although organization and innovation scholars also have contributed to this literature (e.g. Anderson et al., 2006; Davis \& Marquis, 2005; Weber, 2006), we believe that that the field in general can benefit from learning more about developments in neighboring disciplines. This essay provides an overview of the guiding ideas behind this mechanisms movement. We focus particular attention on how these ideas have been applied and articulated in analytical sociology, the area of the social sciences where ideas about mechanism-based explanations have been most thoroughly developed.

Our paper is organized as follows. We first define what we mean with a "mechanism" and we highlight the defining characteristics of a mechanism-based explanation. We then discuss what implications the mechanism view has for theorizing, and we conclude with discussing in some detail how mechanism explanations can contribute to the further development of organizational research.

\section{Mechanisms and mechanism-based explanations}

Before discussing how mechanism ideas currently are used in the social sciences, let us 
emphasize an important distinction between: (1) establishing whether or not two variables or events are causally related to one another, and (2) developing good or acceptable explanations. We want to draw attention to this distinction at the very outset since failure to do so has generated some confusion in the past. The mechanism movement in the social sciences is primarily about explanations, not about causality or methods for establishing causal effects. An important tenet of the mechanism perspective is that good explanations detail how macro outcomes to be explained were brought about. Establishing causal relations often serve an important role in developing such explanations, but establishing a causal relationship rarely is sufficient for arriving at an acceptable explanation. An important motivation for the mechanism approach is that an acceptable explanation of $\mathrm{Y}$ rarely can be arrived at by simply referring to a causal relation between $\mathrm{X}$ and $\mathrm{Y}$, as is commonly done in the so-called 'explanatory accounts of causality' (Pearl, 2000, p. 25-26). Why is this distinction useful? We argue that while explanatory accounts of causality derived from econometric theory has been immensely useful for methodological development in the social sciences, their potential for theoretical generalization and replication remains very limited. Such causal tests of X-Y relationships are usually confined to tests of how variation in a single variable $\mathrm{Y}$ cause change in some outcome variable $\mathrm{Y}$ in the dataset at hand. For example, using quasi-experimental techniques to establish the causal effect of certain types of social movement protests on corporate expansion (Ingram, Yue \& Rao, 2010) or using statistical instrumental-variable techniques to establish the causal effect of political uncertainty on new venture differentiation (Tang \& Wezel, 2015) are extremely useful for many purposes, but when viewed as explanations, they remain black-box explanations since the mechanisms linking the causes to the effects remain opaque. In order to remove the black box we need to specify the relevant types of actors, the type of activities they engage in, what propels them to behave the way they do, and how their behavior collectively bring about the 
macro outcome to be explained, in this case the type of corporate expansion and venture differentiation of concern.

Mechanism thinking and mechanism-based explanations have a long history in the social sciences, but Robert K. Merton is the perhaps most important precursor of the current mechanism movement. Merton not only used the concept of mechanisms as many others also did, but he approached research questions in a similar way as we do today and his views of what theories in the social sciences are all about and what they reasonably can aspire to also resonate well with current ideas. Unlike many of his contemporaries he was not enamored by grand theoretical schemes, nor was he concerned with simple cause-effect relationships. Instead he asked questions of the "how did it come about?" kind and this led him to focus on mechanisms and types of theories suitable for answering such questions, what he referred to as "theories of the middle range"(Merton, 1968a).

In some of his best and most influential work, such as his theory of self-fulfilling prophecies (Merton, 1948) and his theory of Matthew effects (Merton, 1968b), Merton not only sought to identify the static cogs and wheels of the causal machinery, but also the dynamics that the causal machinery was likely to give rise to. For example, Merton showed how an initially false belief about the insolvency of a bank can set in motion a self-reinforcing belief-based process that eventually makes the false belief come true, and how a cumulativeadvantage process that makes those rich in opportunities get even richer can contribute to explaining the highly skewed distribution of status and rewards that are observed in many domains.

These theories have become ideal-typical icons of what mechanism-based explanations is all about because:

1. they clearly and precisely explicate the mechanisms at work,

2. they explicate the dynamic processes that the mechanisms are likely to give rise to, 
3. they are actor and not variable or factor oriented, and

4. they are semi-general and hence portable and able to explain also other types of phenomena than those they initially were developed for.

The main message of this essay is that scholarship in organizational studies would benefit considerably if it sought to develop explanations of this kind.

Merton never developed any clear definition of the mechanism concept, but the current holder of the Merton Chair at Columbia, Jon Elster, has done that. Elster has probably been the single most influential advocate of the mechanism approach in the social sciences, and his writings identified a large number of action-related mechanisms that are important for explaining a wide range of micro as well as macro phenomena (e.g. Elster, 1989). As far as the explanatory model is concerned, Elster's core idea is that a mechanism opens up a black box and shows the cogs and wheels of the internal machinery. In doing so it turns the black box into a transparent box and thereby makes visible how the participating actors bring about the outcome of interest, or how the interaction between various mental states such as beliefs and desires explain why individuals behave the way they do.

The various definitions of the mechanism concept that Elster provided over the years have been a source of some confusion (see Hedström \& Ylikoski 2010). In his early work he viewed mechanisms in terms of continuous and contiguous chains of causal or intentional links between the explanans and the explanandum (Elster, 1989), and this view is in line with the general mechanistic perspective that we are advocating. In contrast, his later definition: “... mechanisms are frequently occurring and easily recognizable causal patterns that are triggered under generally unknown conditions or with indeterminate consequences" (Elster, 1999, p.1) is less appropriate as a general definition of mechanism. One should not require that mechanisms occur frequently or that they are easily recognizable, as sometimes finding underlying mechanisms is the hardest part of the scientific work. Although it often is the case 
that we do not know the conditions under which a specific mechanism is triggered, it makes little sense to incorporate this uncertainty into the very definition of a mechanism.

Hedström (2005) has characterized mechanism and mechanism-based explanations as follows: Mechanisms consist of entities (with their properties) and the activities that these entities engage in, either by themselves or in concert with other entities. These activities bring about change, and the type of change brought about depends upon the properties of the entities and the way in which the entities are organized spatially and temporally. A mechanism-based explanation of an observed outcome refers to the type of mechanism by which such outcomes are regularly brought about (see also Machamer, Darden \& Craver, 2000).

Different kinds of mechanisms can be involved at every stage of the "continuous and contiguous chain of causal or intentional links between the explanans and the explanandum" that Elster referred to, and some sort of categorization of different kinds of mechanisms therefore is needed in order to handle the large variety of mechanisms. Hedström and Swedberg (1998) suggested the typology of mechanisms described in Figure 1 that classifies mechanisms in terms of whether the explanans and the explanandum refer to micro or macro entities.

\section{INSERT FIGURE 1 HERE}

For most of the social sciences, organization and innovation studies included, developing better explanations of the properties characterizing macro entities such as organizations, groups, fields, networks, markets, and audiences are particularly important, in part because 
they are more difficult to explain and therefore more underdeveloped, and in part because it can be argued that they are more central to the social sciences than are the explanation of individual properties (Coleman, 1986). A basic point of the mechanism perspective is that explanations that simply relate macro properties to each other (arrow 4) are unsatisfactory because they do not specify the mechanisms by which macro properties are related to each other. For an explanation to be satisfactory, it must open up the black box and detail the mechanisms that brought about the macro-level outcome to be explained. Instead of analyzing relationships between phenomena exclusively on the macro level, one should (1) identify the situational mechanisms by which the macro environments in which actors are embeddedorganizations, fields, networks, etc.—shape actors' opportunities, goals, beliefs, etc., as well as (2) the action-formation mechanisms that show how these opportunities, goals, beliefs, etc. influence the actor's behavior, and finally (3) the transformational mechanisms that show how the behavior of many individuals jointly bring about various intended and unintended macro outcomes. Only by considering the entire chain of situational, action-formation, and transformational mechanisms, have we explained the observed macro phenomenon.

It should be noted that although micro in Figure 1 refers to actors it does not refer to any fixed category of actors. Depending upon the problem at hand, it could, for instance, be individual persons (micro) who are embedded in organizations (macro) or individual organizations (micro) that are embedded in inter-organizational networks (macro). Collective entities such as fields or networks do not have any agentic capacities of their own, however, so it makes little sense to think of them as the micro-level entities that through their activities being about some macro outcome to be explained.

\section{Mechanisms and the study of processes}

Although Figure 1 may appear as if it simply encouraged researchers to focus their attention 
on estimating three different types of causal effects, the main message is rather the opposite. It is extremely rare that the type of macro outcomes that social scientists seek to explain are caused by events taking place at any single specific point in time - instead such outcomes tend to be generated through processes that unfold over extended periods of time (see also Van de Ven, 1992). In order to avoid non-explanatory black-box accounts, the explanation must clarify how these processes operate, and underlying Figure 1 is the idea that social interactions and various kinds of feedback loops are of core importance. This is more clearly articulated if we make explicit the sequencing of events implied by the figure: Macro properties at time 1 influence an individual's beliefs, values, opportunities, et cetera at time 2; these beliefs et cetera influence how the individual acts at time 3 , and this action has an effect on the macro environment at time 4 which in turn influences other individuals' beliefs, opportunities et cetera at time 5 , their actions at time 6 , the macro environment at time 7 , and so on. Thus, Figure 1 seeks to encourage a shift in focus from the estimation static causeeffect relationships to a focus on the processes through which the macro outcomes to be explained are brought about.

The importance of explicitly analyzing dynamic micro-macro processes was perhaps best exemplified by Thomas Schelling in his analysis of neighborhood segregation processes (Schelling, 1978). He showed that even when focusing on simple and seemingly entirely transparent system, the dynamic processes can be highly complex and the macro outcomes counterintuitive. Schelling showed that even if one knows everything there is to know about the rules governing individuals' behavior it often is extremely difficult to anticipate the macro outcomes they will bring about. A corollary to this is that observed aggregate patterns and statistical associations often may say little about the micro-level processes that brought them about. Schelling's results therefore underscore the importance of using explanatory models that clearly specify the micro mechanism at work and to derive their aggregate dynamic 
implications. Implicitly assuming that explanations of micro behavior also hold true as explanations for macro outcomes is highly error prone. Relying on representative-agent models as often is done in economics or ignoring mechanisms and focusing on type 4 aggregate relationships as often is done in the other social sciences, does not lead to satisfactory scientific explanations in terms of how the (changes) in macro outcomes were brought about.

As Coleman (1986) underscored, the difficulties facing scholars seeking to explain complex processes like these to a large extent is due to the lack of methodological tools for analyzing the link between micro and macro. With reference to Figure 1, research in the mechanism-based tradition has been reasonably successful in addressing both situational and action-formation mechanisms, but when it comes to the link between micro behavior and macro outcomes, the development has been considerably slower. Some advancements have occurred, however, that have increased our ability to analyze complex processes linking micro behavior and macro outcomes to one another. These advancements include new computationally intensive statistical tools, the ability to conduct large-scale and empirically calibrated computer simulations, and increased access to massive data on interacting actors (individuals and organizations) that are followed over extended periods of time. In the below we review some examples of classic and contemporary research in organization and innovation studies that could serve as inspiration for mechanisms-oriented work in organization and innovation studies, some of which make use of these new developments.

\section{Mechanisms in Organization and Innovation studies}

Organization and innovation studies contain several examples of mechanism-oriented studies and organizational scholars have discussed mechanism-oriented research from different theoretical and methodological angles. If we return to Figure 1 and its three types of 
mechanisms, it is obvious that organization research have produced important findings on each of them, and we here briefly discuss some examples of such research.

Organizational ecology is perhaps the most widely known research tradition in organization studies that is based on a rigorous formal theory that focuses on the explanation of macro outcomes. For example, the density-dependence model of organizational ecology views the dynamics of organizational entry, growth, and exit from a macro sociological lens where organizations with similar structural attributes are assumed to compete for resources in a delimited resources space. The equilibrium number of firms according to the density dependence model-the environment's carrying capacity-is given by the number of organizations of a specific type that can be sustained in a particular environment (Hannan \& Carroll, 1992). By tightly linking the theoretical mechanisms of competition and legitimacy to empirical research, organizational ecology is a prime example of organizational research with the kind of dynamic focus we believe to be of crucial importance for future research. While the ecological perspective has been extended to include many interesting thoughts on other relevant mechanisms such as resource partitioning, imprinting effects, and the role of various audiences (Hannan, Polos \& Carroll, 2007), the perspective correctly has been criticized for not empirically examining the mechanisms upon which it rests. Instead ecologists typically have rested with postulating their existence and then examined the accuracy of the macro predictions derived from them. As a consequence, plausible alternative explanations for the dynamics of organizational entry, growth, and exit have not been seriously attended to (Winter, 1990). From the dynamic and longue durée of their analyses some core assumptions also do not seem well founded, such as that of fixed carrying capacities. Arguably, this instrumentalist attitude to theories and models has hampered the development of the approach and the impact the ecological approach could have had on organization researchers at large. 
that systematically links micro behavior and macro outcomes to one another. Networkoriented research comes in many different shapes and forms, but often the focus is on how the structure of inter-organizational or interpersonal ties affect organizational actions and outcomes (e.g. Hedström et al., 2000) or how organizational activities affect the emergence, strength, and persistence of network ties (e.g. Dahlander \& McFarland, 2013). Diffusion researchers study the spread of organizational artifacts or practices across time and space (e.g. Strang \& Meyer, 1993), taking account of both successful (Strang et al., 2014) and nonsuccessful diffusion (Jonsson, 2009). The three types of mechanisms discussed above are at the core of these analyses: (1) the perceived value of adopting a practice in part is seen as a function of the number of prior adopters in the population at large or in a subset of relevant organizations (the situational mechanism), (2) the perceived value of the practice influences the probability of it being adopted (the action-formation mechanism), and (3) the adoption decisions of many organizations alters the macro state (the transformational mechanism), and this influences yet other potential adopters through the same set of mechanisms.

Process tracing studies are bountiful in organization studies and are often based on qualitative in-depth studies that seek to identify and explicate potential causal patterns and how they play themselves out over time. These types of studies tend to use a combination of different approaches such as pattern matching, process tracing, and the constructing of causal narratives (Markus \& Robey, 1988; Van de Ven \& Poole, 2005) ${ }^{1}$. The main strength of such small-N type of process studies are their ability to explicate details of the causal cogs and wheels that would be difficult to do in other ways. These types of studies can show how the cultural, institutional or political environments in which an organization is embedded influence its behavior by identifying relevant situational and action-formation mechanisms (Kim et al., 2016). However, rarely are these insights incorporated into large-N models seeking

\footnotetext{
${ }^{1}$ Consistent with the mechanism-based tradition, we here refer to 'process' as 'explanation of a relationship' (Van de Ven, 1992). It should be acknowledged that there other definition of processes, such as how phenomena change and unfold over time (Tsoukas \& Chia, 2002).
} 
to derive the likely macro-level implications of the micro mechanisms that have been identified. Building large-scale models tested using simulation or real data on many interacting organizations over time on the basis of the findings from process-tracing studies appears as a very promising line of research, but we know of few such attempts since the famous Minnesota studies on innovation (Van de Ven et al., 1999).

Mathematical models have been employed in organization studies since its early inception (March, 2007). Developing formal models of organizational phenomena has many advantages since it forces the analyst to be perfectly clear in definitions and assumed relationships between entities of interest (Harrison et al., 2007), and they can generate insights into dynamic processes that would be difficult to gain in other ways (Maguire et al., 2006). However, from the vantage point of our realist position, the domains within which mathematical modeling fruitfully can be applied appears rather restricted. In our view, mathematical models can play an important role in explanatory research if and only if the assumptions upon which they rest are roughly correct. No matter how parsimonious or elegant the mathematical model is or how well it predicts the outcome of interest, if the model is founded upon empirically incorrect assumptions it will not be explanatory because then it will give a factually incorrect answer to the question of why we observe what we observe.

Agent-based simulations have emerged as an important tool for analyzing processes of the kind depicted in Figure 1. Unlike strict mathematical models, the agent-based formalism does not force the analyst to make assumptions that are known to be untrue at the very outset. Agent-based modeling instead simulates the behavior of adaptive agents who influence one another through their actions, which allows researchers to base the analysis on empirically grounded behavioral assumptions. The first generation of agent-based researchers tended to use highly simplified models that sought to demonstrate theoretical possibilities rather than explaining empirically observed phenomena (e.g. Axelrod, 1997). The dramatically increased 
processing power of computers has transformed the ways in which social science research can be conducted, however. Computers nowadays can be used to analyze and simulate complex, dynamic, and large-scale social systems, and this opens up new possibilities for simulating the behavior of large populations of interacting organizations or individuals. A recent development that holds great promise for the future is the increasing use of large-scale quantitative data analyses to infer the rules governing actors' behavior, and then use these behavioral rules as the foundation of large-scale agent-based simulation models (see Hedström \& Manzo, 2015). This involves four interrelated steps: (1) collect data on large numbers of actors, (2) use this data to assess the mechanisms influencing their behavior, (3) build large-scale simulation models based upon these results, and (4) use the simulations models for conducting virtual 'what-if experiments'.

This approach also allows for investigations of how actors that repeatedly interact over time transform the macro environments in which they are embedded, e.g., organizations, industries, or fields (Colyvas \& Maroulis, 2015; Macy \& Willer, 2002). Recent models have been used by organization researchers to examine how organizational cultures change as a results of selection and retention of employees (Harrison \& Carroll, 2006), how institutional rules and procedures emerge through social interaction (Colyvas \& Maroulis, 2015), the consequences that follow if managerial behavior is simultaneously influenced by professional identities and cultural prescriptions in the workplace (Schneider, 2002), how social influence affects goal settings within and between organizations (March, 1991), and how organizations' adopt managerial fads (Strang \& Macy, 2001), just to mention a few examples.

Big data analysis. Related and complementary to several of the aforementioned strands of organization and innovation studies is the emerging trend of 'big data' analysis in social science. During the last few years we have seen a rapid development in the availability of big data as well as in the methods useful for analyzing such data. One of the primary 
constraints on scholars' abilities to examine dynamic processes of the kind discussed above has been the challenge of collecting data with sufficiently high time resolution on large numbers of interacting individuals or organizations. This constraint is gradually being removed in certain domains through new technologies for data and collection. These new techniques "produce nearly continuous streams of big data [and] offer great promise to liberate researchers from these constraints by producing unprecedented volume, micro-level detail, and multifaceted richness" (George, Haas, \& Pentland, 2014, p. 324). Such data may be used to answer previously largely intractable questions related to the timing and sequencing of events, and actors' behaviour before, during, and after such events (Bearman, 2015). Further and importantly, organizations are increasingly collecting big data for their own internal purposes (Schildt, 2017). This provides new opportunities to tap into such data to examine central topics of interest for researchers in organization and innovation studies, such as the conditions for change and development among different types of organizations (George \& Lin, 2017).

Both secondary data such as those generated by emails, cameras, and positioning systems, as well as primary data collected by researchers to address a specific set of question(s) can provide data streams related to actions and interactions such as individuals' movements and communication with one another (Bengtsson et al., 2015). New technologies facilitate the integration of new types of data (e.g., derived from wearable sensors or computer-aided text analyses of conversations or documents) into our existing repertoire of data-collection techniques such as surveys, interviews, and observations (Mathieu, 2016). Tracking actors' movements and interactions and relating these to various collective outcomes allow for new ways of studying organization and innovation processes that goes beyond the more narrow focus of the experimentally-oriented econometric identification tradition common in much of the field. An organization-level example of such studies is Kleinbaum 
and Stuart's (2014) studies of communication flows within and across departments using detailed longitudinal email traffic in an organization, finding that most email traffic runs through the organization's headquarters. As a field-level example, Aral, Muchnik and Sundararajan (2009) analyzed day-by-day adoption of a mobile service application, finding that previous methods use in diffusion studies tends overestimate peer influence in product adoption and that users' homophily explains most of this effect. One could conceive of scholars soon using similar data from a multitude of organizations to assess macro-level outcomes such as the development and change of organizational fields or ecosystems, as a function of micro-level mechanisms within and between organizations (George \& Lin, 2017).

\section{Discussion}

In this essay we have discussed the potential for mechanism-based explanations in organization and innovation research, providing both an overview of the guiding ideas behind this mechanisms movement and examples of studies within organization and innovation research with mechanism-oriented reasoning from different theoretical and methodological angles. We believe that in addition to serving as an important impetus for better understanding the processes through which the outcomes we seek to explain are brought about, the mechanism perspective has important implications for theoretical advancements. These implications resonate with recent development of problem-driven research in organization studies (Daft \& Lewin, 1990; Davis \& Marquis, 2005; Gulati, 2007; Lawrence, 1992). In organization and innovation studies, various bits and pieces of theories are generally used in order to shed light on the problem at hand, Theory of this kind is not some sort of unified, abstract, hypothetic, and deductive system from which predictions can be deduced, but theory is a toolbox of different kinds of semi-general mechanisms that are of explanatory relevance in certain situations but not in others. 
Identifying and theorizing mechanisms in organization and innovation studies increase the likelihood of middle-range theories with wide applicability emerging from such studies. For example, Cyert and March's early case studies of industrial corporations noted the salience of budgeting behavior and feedback from recent performance of the focal organizational as well as similar organization (March \& Simon, 1958). These mechanisms were later formalized and studied through simulations (e.g. Levinthal \& March, 1981; March, 1991) and was brought to bear on a wide range of organizational phenomenon such as risk taking, innovations, investments, and internationalization attempts. Carefully crafted empirical analyses will assist organization researchers in their efforts to identify a wide range of such organizational mechanisms, and tools such as agent-based modeling will prove useful for deriving likely macro-level implications of small-N studies that indicate when or how a certain mechanism is triggered.

We believe the realist and toolbox view of theory that is an integral part of analytical sociology and is implicit in much of organization studies offers an appropriate way forward for scholars seeking to build and test causal mechanisms of organization and innovation. Aiming for general and unified theories like those in neoclassical economics is likely to generate sophisticated story telling rather than explanations of how outcomes actually are brought about. The complex nature of social and organizational processes calls for analytical tools that will help us in dissecting these processes and the key mechanisms behind them. A central theme in much of organization theory is precisely that macro processes typically are not simple aggregations of micro processes but rather are the result of social interdependencies and complex feedback loops producing outcomes that are difficult to predict ex ante (Davis, 2006).

Given the fact that most organizations are embedded in competitive environments, various sorts of social and economic interdependencies are likely to be of considerable 
importance: the success of one organization often is due to the failure of another organization; legitimacy is important for organizations and is in part a function of doing the same as others; mimicking the successful often is a successful strategy; and so on. When behaviors are interdependent, we are in a Schelling-like world and there are dangers with trying to draw inference from micro to macro and vice versa because of the complexity of the processes, cascades, tipping point effects, and similar well-known nonlinearities (Hannan, Pólos \& Carroll, 2003; McKelvey, 1997). Using simulation models built upon results from more traditional cause- and effect studies makes it possible to derive the short and long term macro implications of the established micro effects and this can generate new and important insights that cannot be inferred from the micro-level effects per se.

\section{Conclusion}

In this essay we have discussed the promise of mechanism-based theorizing for organization and innovation studies. We have highlighted the identifying characteristics of the mechanism approach, its realist stance on explanations, its focus on the dynamic processes through which outcomes to be explained are brought about, and some theoretical and methodological implications of this. The mechanism perspective with its toolbox view of theory and its reliance on both quantitative and qualitative analyses has the potential to serve as integrative force in the rather diversified field of organization and innovation studies. This is particularly so since the same type of mechanism is often labelled differently in different subfields or by different researchers, and this makes the field appear much less orderly and focused than it actually is. For the same reason, a focus on mechanisms also would help to integrate organization studies with other fields of the social sciences. For these reasons we hope organization and innovation scholars will heed to this call for intensified research on mechanisms and the organizational and societal processes they give rise to. 


\section{REFERENCES}

Anderson, P. J., Blatt, R., Christianson, M. K., Grant, A. M., Marquis, C., Neuman, E. J., Sonenshein, S., \& Sutcliffe, K. M. 2006. Understanding Mechanisms in Organizational Research Reflections From a Collective Journey. Journal of Management Inquiry, 15(2): 102-113.

Aral, S., Muchnik, L., \& Sundararajan, A. 2009. Distinguishing influence-based contagion from homophily-driven diffusion in dynamic networks. Proceedings of the National Academy of Sciences, 106(51): 21544-21549.

Axelrod, R. 1997. Advancing the art of simulation in the social sciences, Simulating social phenomena: 21-40: Springer.

Bengtsson, L., Gaudart, J., Lu, X., Moore, S., Wetter, E., Sallah, K., Rebaudet, S. \& Piarroux, R. (2015) Using Mobile Phone Data to Predict the Spatial Spread of Cholera. Nature: Scientific Reports, 5(8923).

Bearman, P. 2015. Big data and historical social science. Big data \& Society, 2(2): 1-5

Colyvas, J. A., \& Maroulis, S. 2015. Moving from an Exception to a Rule: Analyzing Mechanisms in Emergence-Based Institutionalization. Organization Science, 26(2): 601-621.

Daft, R. L., \& Lewin, A. Y. 1990. Can organization studies begin to break out of the normal science straitjacket? An editorial essay. Organization Science, 1(1): 1-9.

Dahlander, L., \& McFarland, D. A. 2013. Ties that last tie formation and persistence in research collaborations over time. Administrative Science Quarterly, 58(1): 69-110.

Davis, G. F. 2006. Mechanisms and the theory of organizations. Journal of Management Inquiry, 15(2): 114-118.

Davis, G. F., \& Marquis, C. 2005. Prospects for organization theory in the early twenty-first century: Institutional fields and mechanisms. Organization Science, 16(4): 332-343.

Elster, J. 1989. Nuts and bolts for the social sciences: Cambridge Univ Press.

Elster, J. 1999. Alchemies of the Mind: Cambridge Univ Press.

George, G., Haas, Martine R., Pentland, A. 2014. Big Data and Management: From the Editors. Academy of Management Journal. 57, (2): 321-326.

George, G., Lin, Y. 2017. Analytics, innovation and organizational adaptation, Innovation: Organization \& Management. DOI: 10.1080/14479338.2016.1252042.

Gulati, R. 2007. Tent Poles, Tribalism, and Boundary Spanning: The Rigor-Relevance Debate in Management Research. Academy of Management Journal, 50(4): 775-782.

Hannan, M. T., \& Carroll, G. 1992. Dynamics of organizational populations: Density, legitimation, and competition: Oxford University Press.

Hannan, M. T., Polos, L., \& Carroll, G. R. 2007. Logics of organization theory: Audiences, codes, and ecologies: Princeton University Press.

Hannan, M. T., Pólos, L., \& Carroll, G. R. 2003. Cascading organizational change. Organization Science, 14(5): 463-482.

Harrison, J. R., \& Carroll, G. 2006. Culture and demography in organizations: Princeton University Press.

Harrison, J. R., Lin, Z., Carroll, G. R., \& Carley, K. M. 2007. Simulation modeling in organizational and management research. Academy of Management Review, 32(4): 1229-1245.

Hedström, P. 2005. Dissecting the social: On the principles of analytical sociology: Cambridge University Press Cambridge.

Hedström, P., \& Manzo, G. 2015. Recent Trends in Agent-based Computational Research: A Brief Introduction. Sociological Methods \& Research, 44(2): 179-185.

Hedström, P., Sandell, R., \& Stern, C. 2000. Mesolevel Networks and the Diffusion of Social 
Movements: The Case of the Swedish Social Democratic Party. American Journal of Sociology, 106(1): 145-172.

Hedström, P., \& Swedberg, R. 1998. Social mechanisms: An analytical approach to social theory: Cambridge University Press.

Ingram, P., Yue, L. Q., \& Rao, H. 2010. Trouble in Store: Probes, Protests, and Store Openings by Wal-Mart, 1998-2007. American Journal of Sociology, 116(1): 53-92.

Jonsson, S. 2009. Refraining from Imitation: Professional Resistance and Limited Diffusion in a Financial Market. Organization Science, 20(1): 172-186.

Kim, P., Wennberg, K., \& Croidieu, G. 2016. Untapped Riches of Meso-Level Applications in Multi-Level Entrepreneurship Mechanisms. Academy of Management Perspectives, 30(3): 273-291.

Kleinbaum, A. M., \& Stuart, T. E. 2014. Inside the black box of the corporate staff: Social networks and the implementation of corporate strategy. Strategic Management Journal, 35(1): 24-47.

Lawrence, P. R. 1992. The Challenge of Problem-Oriented Research. Journal of Management Inquiry, 1(2): 139-142.

Levinthal, D. A., \& March, J. 1981. A model of adaptive organizational search. Journal of Economic Behavior and Organization, 2: 307-333.

Machamer, P., Darden, L., \& Craver, C. F. 2000. Thinking about mechanisms. Philosophy of Science, 67(1): 1-25.

Macy, M. W., \& Willer, R. 2002. From factors to actors: Computational sociology and agentbased modeling. Annual Review of Sociology: 143-166.

Maguire, S., McKelvey, B., Mirabeau, L., \& Öztas, N. 2006. 1.5 Complexity Science and Organization Studies. In S. R. Clegg, C. Hardy, T. Lawrence, \& W. R. Nord (Eds.), Sage handbook of organization studies: 165-214. London: Sage.

March, J. G. 1991. Exploration and exploitation in organizational learning. Organization Science, 2(1): 71-87.

March, J. G. 2007. The study of organizations and organizing since 1945. Organization Studies, 28(1): 9-19.

March, J. G., \& Simon, H. A. 1958. Organizations. Oxford, England: Wiley.

Markus, M. L., \& Robey, D. 1988. Information technology and organizational change: causal structure in theory and research. Management Science, 34(5): 583-598.

McKelvey, B. 1997. Perspective-quasi-natural organization science. Organization Science, 8(4): 351-380.

Merton, R. 1968a. Social theory and social structure. New York: Free Press.

Merton, R. K. 1948. The self-fulfilling prophecy. The Antioch Review, 8(2): 193-210.

Merton, R. K. 1968b. The Matthew effect in science. Science, 159(3810): 56-63.

Pearl, J. 2000. Causality: models, reasoning and inference. Boston: Cambridge University Press.

Schelling, T. C. 1978. Micromotives and macrobehavior: WW Norton \& Company.

Schildt, H. 2016. Big Data and Organizational Design: The Brave New World of Algorithmic Management and Computer Augmented Transparency. Innovation: Organization $\boldsymbol{\&}$ Management, this issue.

Schneider, A. 2002. Behaviour Prescriptions versus Professional Identities in Multi-cultural Corporations: A Cross-cultural Computer Simulation. Organization Studies, 23(1): 105-131.

Strang, D., David, R. J., \& Akhlaghpour, S. 2014. Coevolution in management fashion: an agent-based model of consultant-driven innovation. American Journal of Sociology, 120(1).

Strang, D., \& Macy, M. W. 2001. In Search of Excellence: Fads, Success Stories, and 
Adaptive Emulation. American Journal of Sociology, 107(1): 147-182.

Strang, D., \& Meyer, J. W. 1993. Institutional conditions for diffusion. Theory and society, 22(4): 487-511.

Tang, Y., \& Wezel, F. C. 2015. Up to standard?: Market positioning and performance of Hong Kong films, 1975-1997. Journal of Business Venturing, 30(3): 452-466.

Van de Ven, A. H. 1992. Suggestions for studying strategy process: A research note. Strategic Management Journal, 13(5): 169-188.

Van de Ven, A. H., Polley, D. E., Garud, R., \& Venkataraman, S. 1999. The innovation journey. New York: Oxford University Press.

Van de Ven, A. H., \& Poole, M. S. 2005. Alternative Approaches for Studying Organizational Change. Organization Studies, 26(9): 1377-1404.

Weber, K. 2006. From Nuts and Bolts to Toolkits: Theorizing With Mechanisms. Journal of Management Inquiry, 15(2): 119-123.

Winter, S. G. 1990. Survival, selection, and inheritance in evolutionary theories of organization. In J. V. Singh (Ed.), Organizational evolution: New directions: 269297. Newbury Park, CA: Sage. 
(4)

Macro:

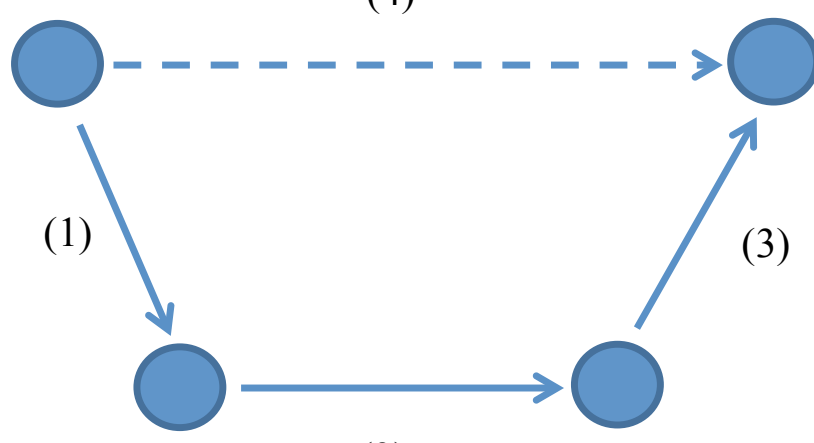

(3)

Figure 1. Types of mechanisms involved in social-science explanations. 